\title{
Estimation of the soil strength parameters in Tertiary volcanic regolith (NE Turkey) using analytical hierarchy process
}

\author{
Hakan Ersoy ${ }^{1, *}$, Melek Betül $\mathrm{Karsli}^{2}$, Seda Çellek ${ }^{1}$, \\ Bilgehan Kul ${ }^{1}$, İdris Baykan ${ }^{1}$ and Robert L PARsons ${ }^{3}$ \\ ${ }^{1}$ Department of Geological Engineering, Karadeniz Technical University, Trabzon 61080, Turkey. \\ ${ }^{2}$ Geological Engineering Department, Gümüshane University, Gümüşhane 29000, Turkey. \\ ${ }^{3}$ Civil, Environmental and Architectural Engineering, University of Kansas, Learned Hall, \\ $1530 \mathrm{~W}$ 15th Street, Room 2150, Lawrence, KS 66045, USA. \\ ${ }^{*}$ Corresponding author. e-mail: blavetirraa@hotmail.com
}

Costly and time consuming testing techniques and the difficulties in providing undisturbed samples for these tests have led researchers to estimate strength parameters of soils with simple index tests. However, the paper focuses on estimation of strength parameters of soils as a function of the index properties. Analytical hierarchy process and multiple regression analysis based methodology were performed on datasets obtained from soil tests on 41 samples in Tertiary volcanic regolith. While the hierarchy model focused on determining the most important index properties affecting on strength parameters, regression analysis established meaningful relationships between strength parameters and index properties. The negative polynomial correlations between the friction angle and plasticity properties, and the positive exponential relations between the cohesion and plasticity properties were determined. These relations are characterized by a regression coefficient of 0.80 . However, Terzaghi bearing capacity formulas were used to test the model. It is important to see whether there is any statistically significant relation between the calculated and the observed bearing capacity values for model testing. Based on the model, the positive linear correlation characterized by the regression coefficient of 0.86 were determined between bearing capacity values obtained by direct and indirect methods.

\section{Introduction}

The shear resistance of soil is the result of friction and the interlocking of particles and, possibly, cementation or bonding at the particle contacts. The shear strength parameters of soils are defined as cohesion (c) and the friction angle (Ø). The shear strength of soil depends on the effective stress, drainage conditions, density of the particles, rate of strain, and direction of the strain. Thus, the shearing strength is affected by the consistency of the materials, mineralogy, grain size distribution, shape of the particles, initial void ratio and features such as layers, joints, fissures and cementation (Poulos 1989).

However, the consistency of soils is dependent on the weight of the water per unit weight of solid material. Because it is often highly dependent on the amount of soil water, consistency is an important property and is a useful measure for

Keywords. Empirical relation; plasticity; regression analysis; strength parameters; Trabzon. 
the processing of very fine clayey soils. Hence, the Atterberg limits of soils, especially the liquid limit (LL) and the plastic limit (PL), define the upper and lower limits, respectively, of the plastic range of a soil. The numerical difference between these two limits expresses the plasticity of a soil and is termed the plasticity index (PI). Plasticity and cohesion reflect the soil consistency and workability of the soils. However, these properties of the soils play an essential role in many engineering projects, such as the construction of the clay core in an earth fill dam, the construction of a layer of low permeability covering a deposit of polluted material, the design of foundations, retaining walls and slab bridges, and determining the stability of the soil on a slope.

Determining the engineering properties of soils, especially strength characteristics, has become one of the most important elements of geotechnical studies. The estimation of some of the basic engineering properties of soils, such as their cohesion and friction angle, requires the preparation of numerous samples and the use of expensive laboratory equipment. The plasticity of a soil is commonly correlated with the expansive potential and internal friction angle for drained field conditions (Gibson 1953; Kenney 1959, 1967; Deere and Patton 1971; De and Furdas 1973; Voight 1973; Mitchell 1976; Holtz and Kovacs 1985; Skempton 1985). However, many researchers have attempted to determine both empirical and theoretical formulations to estimate the nonlinear change in the cohesion of soils (Gan and Fredlund 1988; Escario and Juca 1989; Oberg and Sallfors 1997; Khallili and Khabbaz 1998; Wilbourn et al. 2007) and to predict the soil cohesion using hyperbolic equations (Miao et al. 2002; Lee et al. 2003). Many authors have determined certain relationships between the $\mathrm{P}$-wave velocity and the Atterberg limits of soils (Luna and Jadi 2000; Wesley 2003; Fener et al. 2005; Sawangsuriya and Fratta 2006; Kurtuluş et al. 2009). Thus, it is obvious that the determination of these important properties in easy and economical ways will be of considerable advantage to geotechnical engineers.

During the past 20 years, the industrialization, economic development and significantly increasing population in Trabzon City (NE Turkey) have caused some problems such as insufficient infrastructure, dense traffic and pollution. Of the 81 cities in Turkey, Trabzon is number 62 in terms of surface area, but it is number 5 in terms of population density. The annual population increase rate is $3 \%$, and the population is almost 1 million as of 2012 . Therefore, residence construction has increased by $300 \%$ in the past 10 years. Thus, in the urban areas, especially in the rapidly urbanizing regions of the city, problems and issues of settlement are of immediate importance because Tertiary volcanic regolith can be found in abundance in the city center, especially in the eastern part of the city. In this study, the geotechnical properties of these soils in the city were determined and empirical relationships between the strength parameters and plasticity properties of clayey soils were developed for practical use.

\section{Methodology}

\subsection{Geology and sampling location}

The study area around Trabzon City consists of Tertiary volcano-sedimentary rocks and related Plio-Quaternary regolith and Pliocene deposits containing sandstones, claystones, conglomerates and agglomerates (figure 1). The dominant lithologies in the Tertiary aged unit are basaltic, andesitic volcanic rocks. The Plio-Quaternary altered regolith horizon overlying the Tertiary volcanic rocks in the study area contains the unconsolidated mantle of weathered volcanic rocks (saprolite) and soil material. The thickness of the regolith, including both the soil itself and the saprolite, is approximately $5-10 \mathrm{~m}$ in the region, and the reddishbrown saprolites do not exceed a thickness of 2-3 m (figure 2).

Volcanic saprolites forming in the lower zones of the soil horizons and representing the deep weathering of the bedrock surface are widely exposed in the vicinity of the city. In most outcrops, its reddish brown colour is due to ferric compounds (Arslan et al. 2006). Kaolin minerals dominate the clay fraction of the reddish-brown soils. Chlorite, smectite, pyrophyllite and analcime are sometimes detected in minor quantities. Illite, hematite and amphibole also occur as accessories (Arslan et al. 2006). Most of the undisturbed residual soils obtained from the volcanic regolith on the Tertiary basic volcanic rocks were examined considering the empirical approach of the relations between soil strength parameters and plasticity properties.

\subsection{Particle size distribution, plasticity and index properties}

To establish relations between strength parameters and plasticity properties, soil tests were performed on 41 undisturbed soil samples from the PlioQuaternary regolith in Trabzon city (NE Turkey). Sieve analysis is a procedure used to assess the particle size distribution of a granular material. Sieve and hydrometer analyses were undertaken to determine the grain size of the soil in the studied area. The grain size distributions of the soil were determined by separating the particles using a conventional sieve, a fine sieve, and hydrometer methods. 


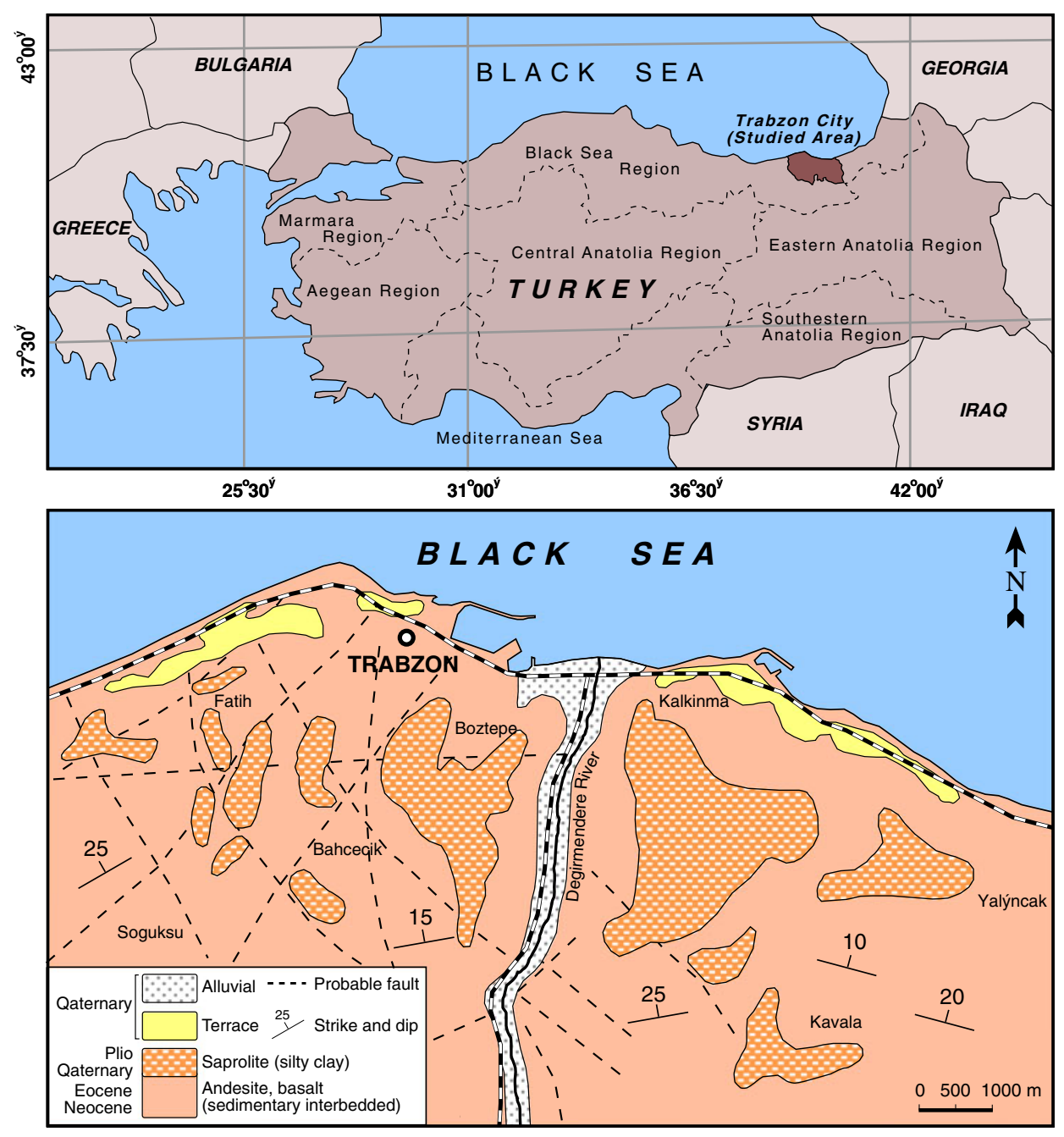

Figure 1. Location and geological map of the study area.

The liquid limit is defined as the minimum moisture content at which a soil will flow upon application of a very small shearing force, and it is the water content where a soil changes from a plastic to liquid behaviour. The plastic limit is also the water content where soil starts to exhibit plastic behaviour. The studied samples were analyzed to measure the natural unit weight $(\gamma \mathrm{n})$, specific gravity $(\mathrm{G})$, liquid limit (LL), plastic limit (PL), plasticity index $(\mathrm{PI})$ and moisture content $(\mathrm{w})$. In the laboratory studies, these properties of the studied clayey soils were determined in accordance with the standards of D422, D4318 and D4718 (ASTM $1991 \mathrm{a}, \mathrm{b}, \mathrm{c}$ ), and the laboratory test results are given table 1.

The sieve methods and hydrometer analysis show that the samples are composed of 1-5\% gravel, $11-20 \%$ sand, $20-30 \%$ silt and $31-50 \%$ clay sized materials (figure 3a). The specific gravity of the samples in the fine-grained materials is determined to be approximately 2.36-2.61, which may have been influenced mainly by the presence of a small quantity of organic materials. Clay materials were classified according to their plasticity index and liquid limit via the plasticity chart as depicted in figure 3(b). According to the chart, most of the samples contain illite and kaolinite type clay minerals and, rarely, montmorillonite. Some of the samples are plastic, and others are high plastic according to the classification of Leonards (1962) and IAEG (1976). The liquid limits are between $33 \%$ and $90 \%$. The plasticity index extended from $10 \%$ to $40 \%$. Skempton (1953) observed that the plasticity index of a soil increases linearly with the percentage of the clay-sized fraction. Skempton defined a quantity called activity, which is the slope of the line correlating PI and percent of the materials finer than $2 \mu \mathrm{m}$. The activity values of the studied clays were calculated between 0.50 and 1.30. Thus, materials with these activity values are generally inactive (Skempton 1953), but they provide a low-medium swelling potential according to 


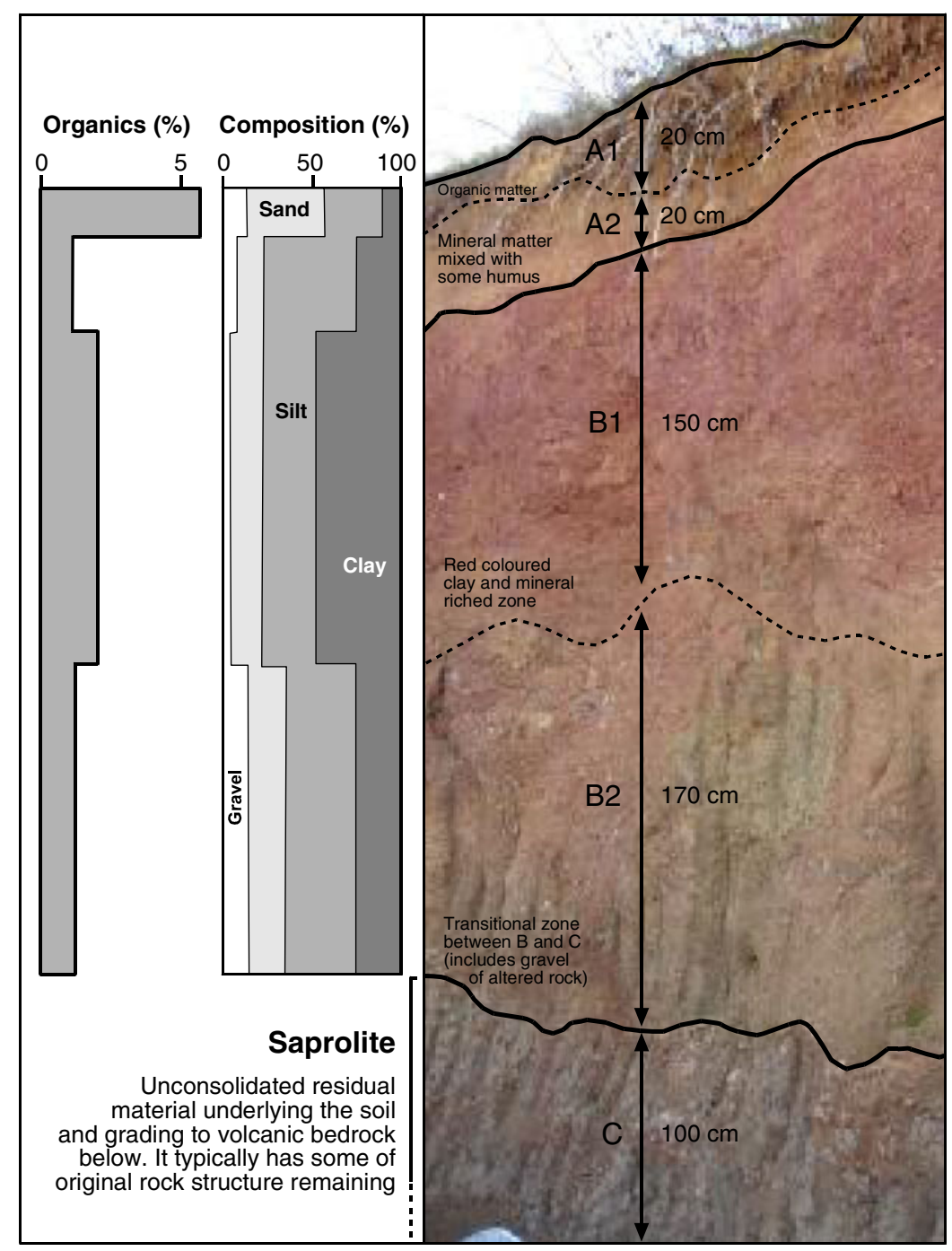

Figure 2. Regoliths including both of the soil itself and saprolite.

Table 1. Some index and strength properties of the studied soils.

\begin{tabular}{|c|c|c|c|c|c|c|c|c|c|c|c|c|}
\hline & \multicolumn{3}{|c|}{ Atterberg limits $\%$} & \multicolumn{4}{|c|}{ Grainsize distribution \% } & \multirow{2}{*}{$\begin{array}{c}\mathrm{c} \\
\left(\mathrm{kN} / \mathrm{m}^{2}\right)\end{array}$} & \multirow{2}{*}{$\begin{array}{c}\varnothing \\
\text { (Degree) }\end{array}$} & \multirow{2}{*}{$\begin{array}{c}\mathrm{w} \\
(\%)\end{array}$} & \multirow[b]{2}{*}{$\mathrm{G}$} & \multirow{2}{*}{$\begin{array}{c}\gamma \mathrm{n} \\
\left(\mathrm{kN} / \mathrm{m}^{3}\right)\end{array}$} \\
\hline & LL & PL & PI & Clay & Silt & Sand & Gravel & & & & & \\
\hline Max. & 90 & 51 & 40 & 50 & 30 & 20 & 5 & 50 & 40 & 55 & 2.61 & 19 \\
\hline Min. & 33 & 18 & 10 & 35 & 20 & 11 & 1 & 2 & 7 & 29 & 2.36 & 16 \\
\hline Mean. & 58 & 35 & 23 & 40 & 26 & 14 & 3 & 31 & 23 & 30 & 2.53 & 17.5 \\
\hline Std. dev. & 14 & 12 & 9 & 7 & 5 & 4 & 0.2 & 16 & 11 & 11 & 0.09 & 1.65 \\
\hline
\end{tabular}

LL and PL: liquid and plastic limit; c: cohesion; $\varnothing$ : friction angle; w: water content; G: specific gravity; $\gamma \mathrm{n}$ : unit weight.

the swelling potential chart developed by Van Der Merve (1964) as depicted in figure 3(c).

\subsection{Shear strength parameters}

The shear strength is the main parameter for understanding the behaviour of a soil mass. The shear strength parameters of a soil are cohesion (c) and the angle of friction $(\phi)$. The conventional triaxial test is a common laboratory testing method widely used for obtaining shear strength parameters for a variety of soil types under drained or undrained conditions. The triaxial test involves subjecting a cylindrical soil sample to radial stresses (confining pressure) and controlled increases in axial stresses or axial displacements. In this study, to obtain the residual shear strength parameters, drained triaxial tests were performed on 41 undisturbed samples collected from different areas in accordance with the standard of 

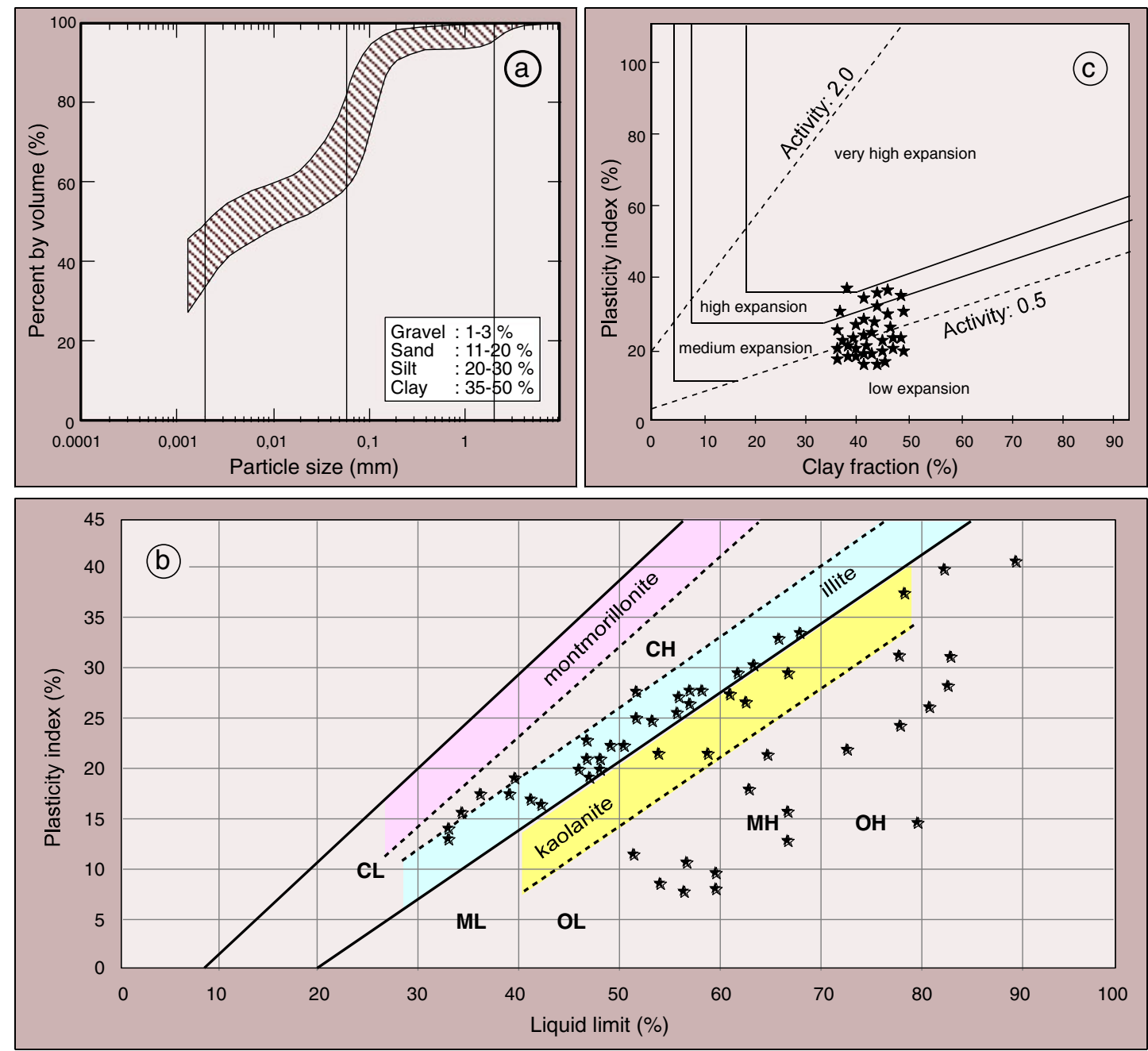

Figure 3. Grain size distributions curves of the soils (a), distributions of the samples on plasticity chart (b) and swell potential chart proposed by Van Der Merve (1964) (c).

D2850 (ASTM 2007). According to the triaxial test results, the cohesion of the soils are between 10 and $51 \mathrm{kPa}$, friction angles are between 7 and 40 (table 1).

\section{Results}

\subsection{Establishment of the analytical hierarchy process}

A number of different evaluation methods have been developed to select suitable parameters among all parameters in complex decision problems. Generally these methods are the linear vector approach (Zieman 1971; Odum et al. 1976; Whitlatch 1976), the matrix method (Leopold et al. 1971), fuzzy set theory (after Zadeh and Tanaka 1975), checklist methods (Dee and Drobny 1972), parametric ranking methods (Mc Bean and Zukovs 1983) and multicriteria decision analysis
(Linkov et al. 2004). The analytic hierarchy process (AHP), a type of multi criteria analysis, was developed by Thomas Saaty in 1980 to standardize the multicriteria decision making process. AHP is a widely accepted decision making method, which is utilized to determine the relative importance of the criteria in a specified decision making problem. Not many years ago, since its introduction in the late 1970s, AHP has been applied in a wide variety of practical problems to model complex decision problems. This process has led many applications in diverse areas such as health care, urban planning (Cook et al. 1984) and space exploration. AHP can also be used in rock and soil mechanic models. AHP completely aggregates various facets of the decision problem into a single objective function. The goal is to select the alternative that results in the greatest value of the objective function. AHP is a compensatory optimization approach. However, AHP uses a quantitative comparison method that is based 
on pairwise comparisons of decision criteria, rather than utility and weighting functions.

Regression analysis includes any technique for modeling and analyzing several variables, where the focus is on the relationship between a dependent variable and one or more independent variables (Freedman 2005). Multiple regression is aimed at learning more about the relationship
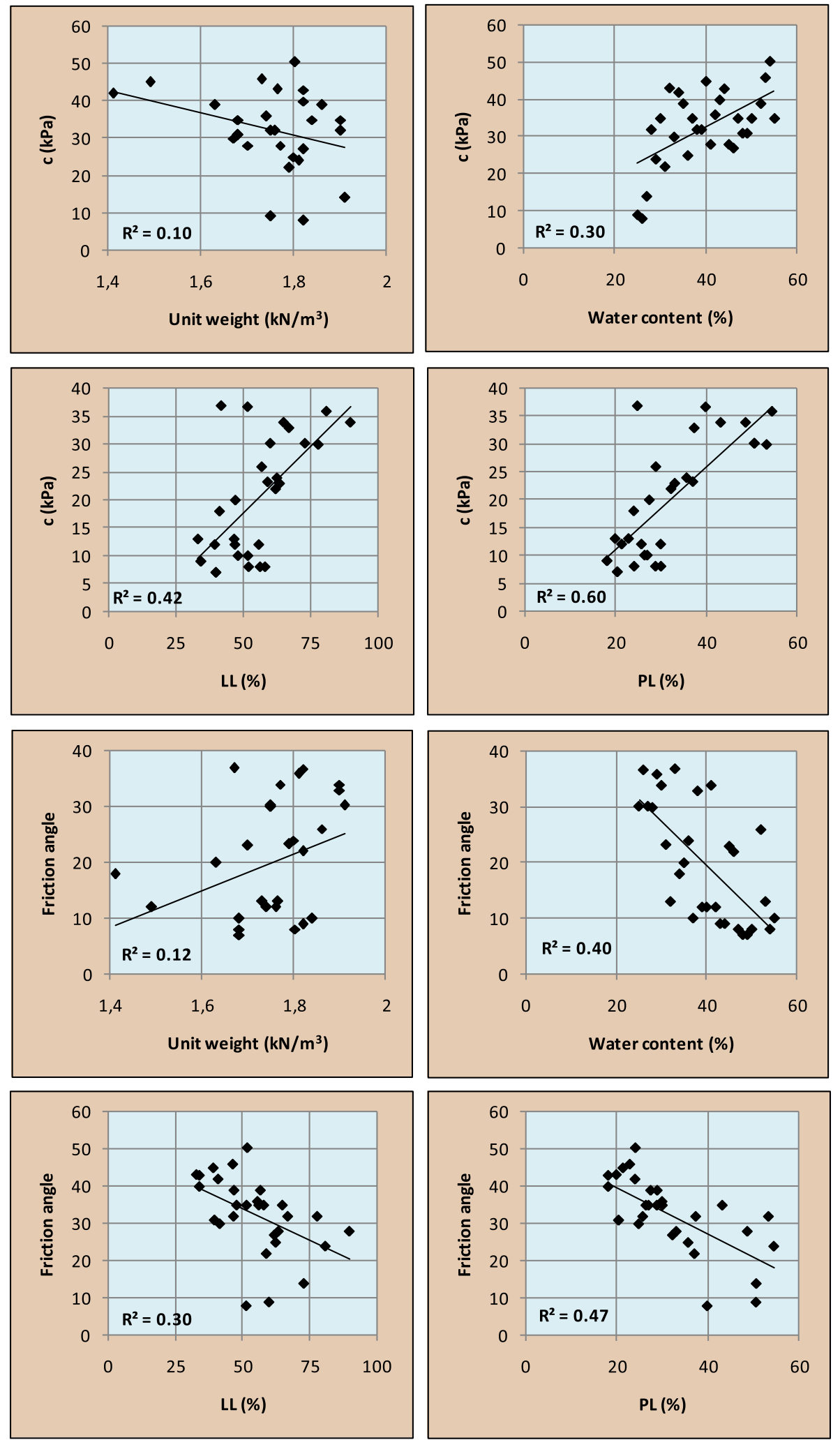

Figure 4. The empirical relationship among the strength parameters and some index properties of the studied soils. 
between several independent or predictable variables and a dependent or criterion (Davis 1986). Regression analysis was used in this study with AHP, a widely accepted decision making method. Constraints are compared to each other in AHP, to designate each variable's relative importance in accomplishing an overall goal. Numerical values were assigned to each pair of constraints using established guidelines and a constrained matrix is built. The sum of each column within the matrix was then normalised and weighting was calculated. Mathematic formulation (simple additive weighting) was defined following an equation for calculating final grading values in multiple criteria problems (Saaty 1980);

$$
v(y)=\sum_{j=1}^{q} w_{j} y_{i j}
$$

where $v(y)$ is area's suitability index, $w$ is a criterion's weighting or importance factor of $a, y$ is a criterion's degree or compliance level, $i$ is the criterion number and $q$ is the number of criteria.

Pairwise comparisons were used to determine each criterion's relative importance; AHP is based on such approach. Decision makers can quantify their opinions about the criteria magnitude by using a verbal scale when comparing pairs of criteria. The pairwise comparison matrix (PCM) constructed by decision-makers is expressed in the following attributes;

$$
w_{i j}=w_{j i}^{-1} .
$$

The next step was to calculate the criteria's relative importance weighing implied by previous comparisons. Saaty (1980) proposed estimating PCM's right principal eigenvector which can be approximated using the geometric mean for each row of the PCM (by multiplying the elements in each row and then taking the $n$th root, where $n$ is the number of criteria). This mode is known as multiplicative AHP (Saaty and Millet 2000) and was used in the present work. The calculated geometric means were then normalised and relative importance weighing extracted. Integrating site selection criteria was based on multicriteria assessment methods (Eastman et al. 1995):

$$
\begin{gathered}
S_{k}=\left(\sum_{i} f i * w i \prod_{j} r j\right) k \\
S=\sum\left(S_{k} * w_{k}\right)
\end{gathered}
$$

where $S_{k}$ is the land's suitability for landfill for objective $k$ (priority groups), $(f)_{k}$ is factor $i$ (discriminating features) for objective $k,(w i)_{k}$ is the weighting for factor $i$ (score given experimental studies) for objective $k,(r j)_{k}$ is constraint $j$ for objective $k$ (value 0 or 1 ), $S$ is multiobjective suitability and $w_{k}$ is the weighting for objective $k$.

Thus, before the multiple regression analysis, it is significant to determine weight percent of explanatory variables on dependent variable for establishing the empirical model. In order to decide which material properties are selected as explanatory variables among the index properties of the soils, AHP was performed using the data obtained from linear regression analyses results (figure 4). Table 2 lists the priority vectors of all criteria and the relative importance weighings are included in the final column of this table. The AHP parameters are also shown in the table, indicating that the judgements (and therefore the final relative importance weighings) seem to be reasonable. The AHP analyses show that the most important criteria affecting on strength parameters of the rocks are plastic limit (PL) with $45 \%$ weight and liquid limit (LL) with $28 \%$ weight. The weights of the other index properties are not more than $20 \%$.

\subsection{Empirical relations between soil plasticity and strength parameters}

The index, plastic and strength properties, which are known as the geotechnical properties of soils, are used as inputs in the solution of various engineering problems. However, the experimental determination of strength parameters such as the cohesion and internal friction angle can provide inaccurate results, especially due to difficulties in obtaining undisturbed samples. Besides, the regularly used methods such as direct shear test and triaxial compressive test require expensive equipments and the application of these tests is time consuming. Therefore, many researchers use statistical analyses, especially regression analysis, to determine the strength parameters of soils and rocks.

In this study, certain numerical relations between the strength and plasticity properties of the studied soils were established to achieve more rapid and practical solutions for the prediction of soil cohesion and the friction angle, and multiple

Table 2. Pairwise comparison matrix and relative importance weighing for index properties of the studied soils.

\begin{tabular}{llllccc}
\hline & \multicolumn{1}{c}{ A } & \multicolumn{1}{c}{ B } & C & D & Eigenvector & Weight \\
\hline A & 1 & 2 & 3 & 5 & 2.34 & 47 \\
B & $1 / 2$ & 1 & 2 & 4 & 1.41 & 28 \\
C & $1 / 3$ & $1 / 2$ & 1 & 4 & 0.90 & 18 \\
D & $1 / 5$ & $1 / 4$ & $1 / 4$ & 1 & 0.33 & 7 \\
\hline
\end{tabular}

$\mathrm{A}$ and B: plastic and liquid limits; C: water content; D: unit weight. 
regression analyses were carried out on datasets obtained from laboratory studies. An independent variable is the variable that is changed in a scientific experiment to test the effects on the dependent variable. A dependent variable is the variable being tested in a scientific experiment. However, the dependent variable is 'dependent' on the independent variable. As the experimenter changes the independent variable, the change in the dependent variable is observed and recorded. While applying regression analysis, the internal friction angle and cohesion are taken as dependent variables
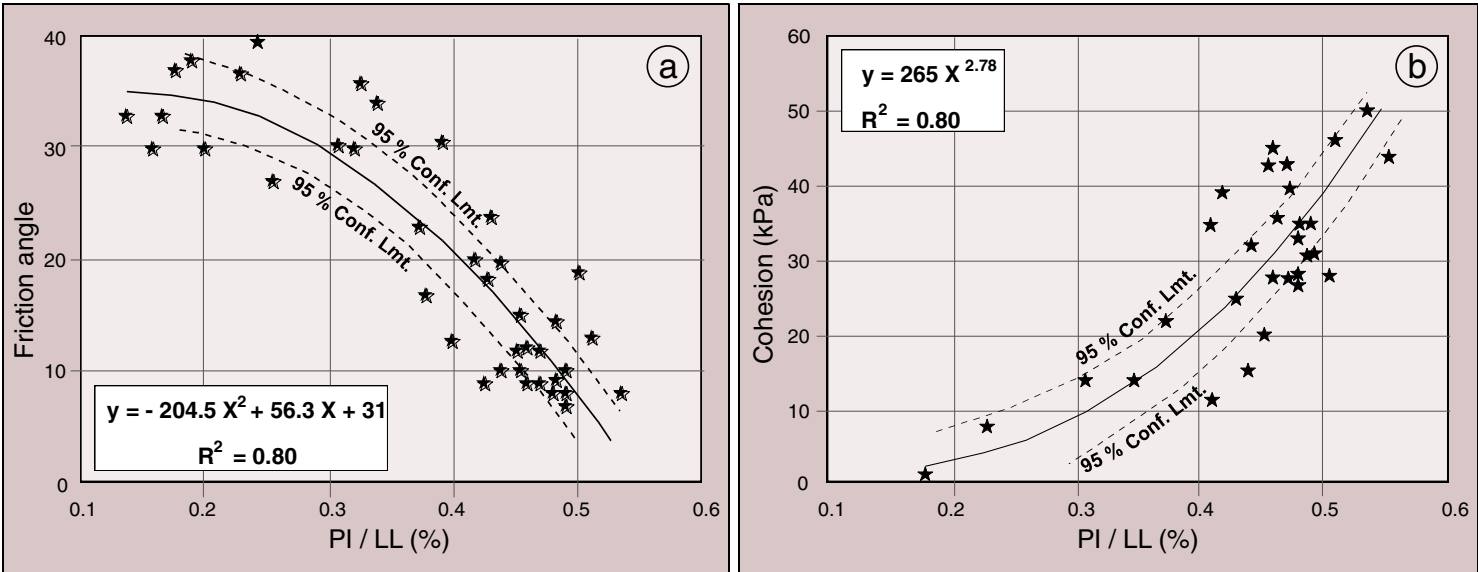

Figure 5. (a) A negative polynomial correlation between PI/LL and friction angle and (b) a positive exponential relation between PI/LL and cohesion.
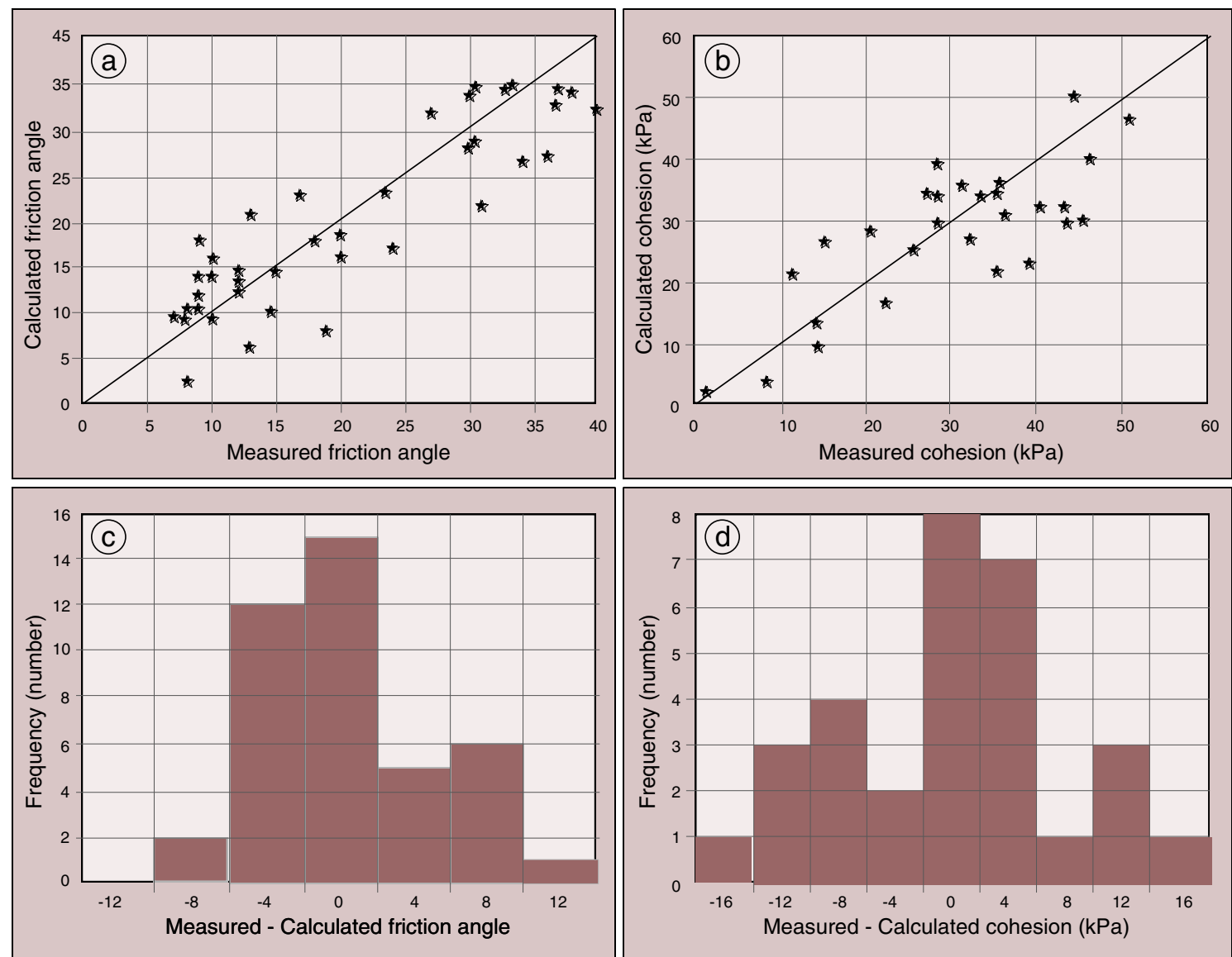

Figure 6. Line-scatter plot diagrams of observed-expected values for friction angle and cohesion of the studied soils (a and b) and histograms of difference between observed and expected values for friction angle and cohesion (c and $\mathbf{d}$ ). 
and the plastic properties of the soil are taken as independent variables.

According to the multiple regression analysis results, a negative polynomial correlation between $P I / L L$ and the friction angle (figure 5a) and a positive exponential relationship between $P I / L L$ and cohesion were observed (figure $5 \mathrm{~b}$ ). These relationships are characterized by a regression coefficient of 0.80 and are represented by the following formulas:

$$
\begin{gathered}
\varnothing=-204.5(P I / L L)+56.3(P I / L L)+31 \\
c=0.265(P I / L L)^{2.78}
\end{gathered}
$$

where $\varnothing$ is the friction angle, $c$ is the cohesion $(\mathrm{kPa}), P I$ is the plasticity index and $L L$ is the liquid limit.

A test of goodness-of-fit establishes whether an observed frequency distribution differs from a theoretical distribution. However, the suitability of a model is tested using the difference between observed and expected values. The normal distribution is a continuous probability distribution that is often used as a first approximation to describe real-valued random variables that tend to cluster around a single mean value. Thus, a normal distribution is expected in the histograms of differences between observed and expected
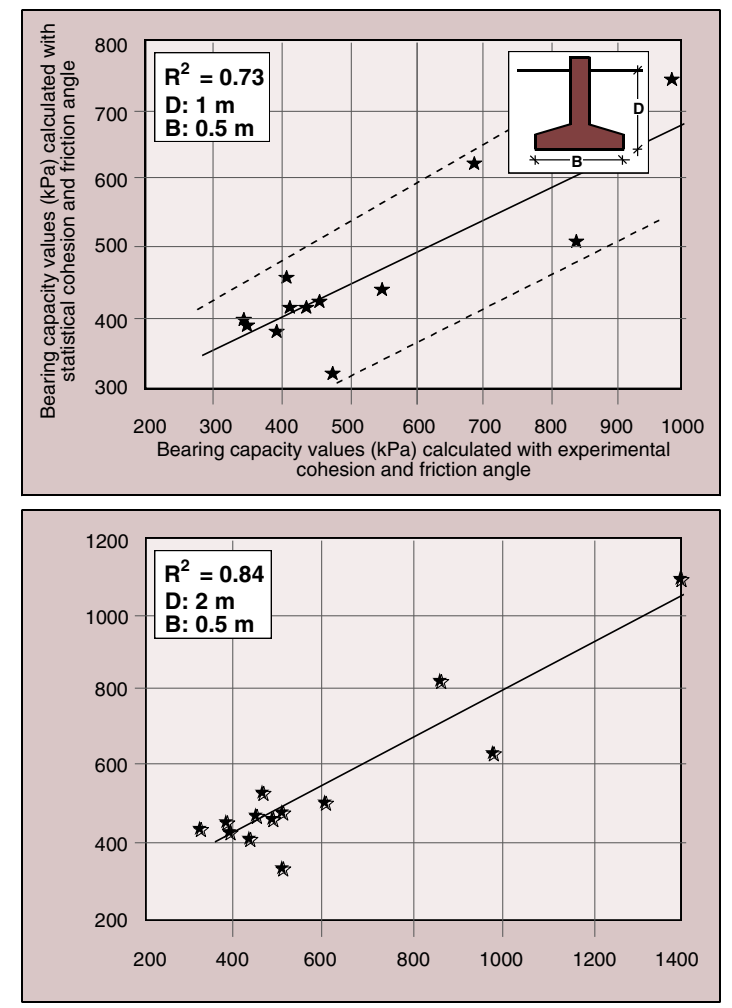

values (Chang et al. 2006). In this study, observedcalculated value graphs are prepared to test the accuracy of the equations determined in the regression analysis. Afterwards, the line at which the regression coefficient is 1 and the lines obtained at the end of the analysis are compared (figure 6a and $b$ ). When these graphs are interpreted, it is observed that the lines drawn at the end of the analysis are approximately parallel to the line at which the regression coefficient is 1 . Moreover, percentage distribution histogram graphs related to the difference of the observed and calculated values are drawn (figure 6c and d), and it is observed that the data show a normal distribution. All of these data show the accuracy and usability of the produced model.

\subsection{Model testing}

There are statistically significant relationships with a regression coefficiency of $80 \%$ between the plastic properties and strength parameters of the soils. Nevertheless, there is need for testing the usability of the strength parameters that have been determined statistically in terms of engineering applications such as slope stability and foundation design. However, the bearing capacity formulas were applied for testing the usability in this
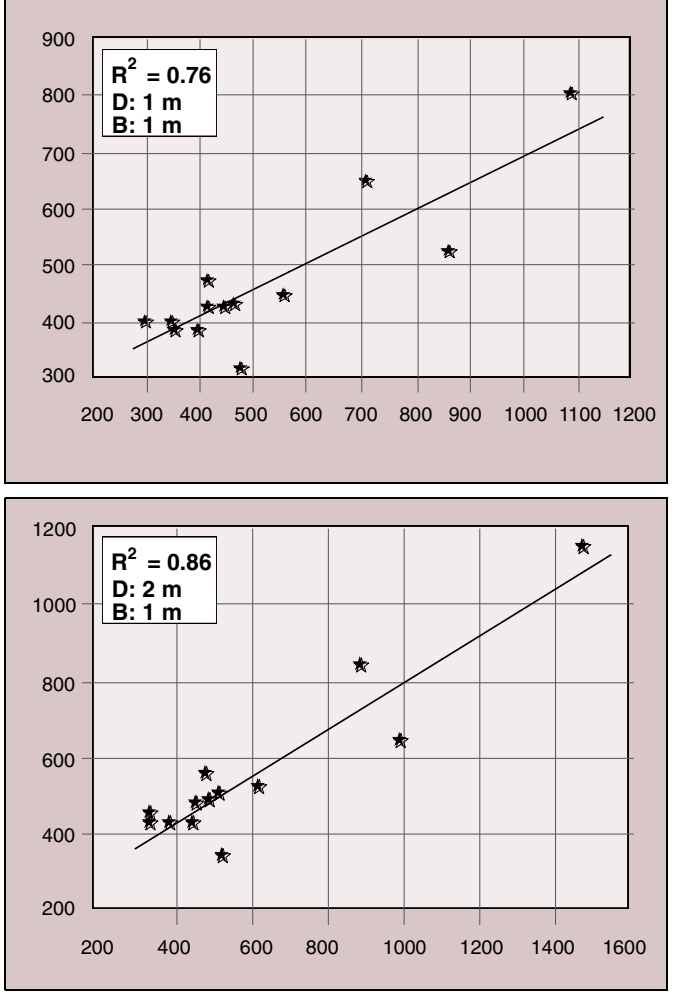

Figure 7. The correlation between the bearing capacity values obtained from experimental and statistical analysis for different foundation conditions. 
study. Terzaghi (1943) was the first to present a comprehensive theory for the evaluation of the ultimate bearing capacity of rough, shallow foundations. This theory states that a foundation is shallow if its depth (Df) is less than or equal to its width (B). However, studies conducted since then have shown that, for shallow foundations, the Df/B can be as large as 3 to 4 (Das 2007). Thus, the bearing capacity values were calculated with the help of Terzaghi by using the soil strength parameters that were primarily obtained through the experimental studies. This process was repeated by using the soil strength parameters that were obtained through the statistical analyses.

Using Terzaghi equations, bearing capacity calculations for different foundation dimensions were made to test the model formed as a result of the statistical studies in the application field. The values 1 and $2 \mathrm{~m}$ for the foundation depth and $0.5 \mathrm{~m}$ and $1 \mathrm{~m}$ for width were used because they are the shallow foundation dimensions often used in practice. However, a strip footing was chosen as the type of foundation, unit weights of the soil were taken as $17.5 \mathrm{kN} / \mathrm{m}^{3}$, and a deep groundwater condition was considered for the study. The bearing capacity values calculated with the two different methods were compared, and it was observed that there was a statistically significant relation between the different methods. The regression values were found to be 0.73 and 0.86 for these statistical relations (figure 7).

\section{Conclusions}

In the study, 41 undisturbed and disturbed soil samples are collected from the regolith on alkaline volcanic in the Trabzon district of Turkey, and laboratory studies were conducted for the determination of the soil properties. However, the empirical equations are proposed using statistical and multicriteria analysis based methodology for the prediction of strength parameters as a function of the index properties of clayey soils in this study. According to the results of multiple regression analysis and analytical hierarchy process, the correlations characterized by the regression coefficient of 0.80 were determined among the friction angle, cohesion and plasticity properties. The study indicates that cohesion and the friction angle can be estimated from their plasticity properties with mathematical relations.

Although there are significant relationships between the plastic properties and strength parameters of the soils, there is need for testing the usability of the strength parameters that have been determined statistically considering geotechnical applications. Because Terzaghi-bearing capacity formulas for the shallow foundation often used in practice, these formulas were used for testing the accuracy of the empirical relations in the study. Thus, the bearing capacity values for different foundation dimensions were calculated by using the soil strength parameters that were firstly obtained through the experimental studies under a deep groundwater condition, and this process was repeated by using the soil strength parameters that were obtained through the analytical hierarchy and statistical analyses-based methodology. The values obtained with the two different methods were compared, and it was observed that there was a statistically significant relation with a regression coefficiency of $86 \%$.

The methodology defined in the study proves to be an appropriate alternative to the quantitative estimation of shear strength parameters, and it avoids the need for time consuming and tedious laboratory testing, especially in engineering practices such as the foundation design projects.

\section{References}

Arslan M, Kadir S, Abdioğlu E and Kolayli H 2006 Origin and formation of kaolin minerals in saprolite of Tertiary alkaline volcanic rocks Eastern Pontides (NE Turkey); Clay Minerals 41 597-617.

ASTM (American Society for Testing and Materials) 1991a Annual Book of ASTM Standards; ASTM Publication, Sect. 4, Vol. 04.08, Philadelphia.

ASTM (American Society for Testing and Materials) 1991b Annual Book of ASTM Standards, D4318 Standard Test Methods for Liquid Limit, Plastic Limit and Plasticity Index of Soils; ASTM Publication, 18p.

ASTM (American Society for Testing and Materials) 1991c Annual Book of ASTM Standards, D4718-87 (Reapproved 2001) Standard Practice for Correction of Unit Weight and Water Content for Soils Containing Oversize Particles, ASTM Publication, 3p.

ASTM (American Society for Testing and Materials) 2007 Annual Book of ASTM Standards, Standard Test Method for Unconsolidated-Undrained Triaxial Compression Test on Cohesive Soils; ASTM Publication, 7p.

Chang C, Mark D, Zoback A and Abbas K B 2006 Empirical relations between rock strength and physical properties in sedimentary rocks; J. Petrol. Sci. Eng. 51 223-237.

Cook T, Falchi P and Mariano R 1984 An urban allocation model combining time series and analytic hierarchical methods; Manag. Sci. 30(2) 198-208.

Das B 2007 Principles of Foundation Engineering; 6th edn, Cengage Publisher, New York, 256p.

Davis J C 1986 Statistics and Data Analysis in Geology; John Wiley Press, USA, 644p.

De P K and Furdas B 1973 Discussion of correlation between Atterberg plasticity limits and residual shear strength of soils; Geotechnique 23 600-601.

Dee N and Drobny N 1972 Environmental assessment for effective water quality management planning, Project completion rep. to U.S. Environmental Protection Agency, Columbus, Ohio, 24p.

Deere D U and Patton F D 1971 Slope stability analysis in residual soils; Proceedings of the 4 th Panamerican Conference on Soil Mechanics (San Juan PR), pp. 144-145. 
Eastman J R, Jin W, Kyem P A K and Toledano J 1995 Raster procedures for multi-criteria/multi-objective decisions; Photogram. Eng. Remote Sens. 61 539-547.

Escario V and Juca N 1989 Shear strength and deformation of partly saturated soils; Proceedings of the 12th International Conference on Soil Mechanics and Foundation Engineering (Rio de Janerio) 2 243-246.

Fener M, Kahraman S, Bay Y and Gunaydin O 2005 Correlations between P-wave velocity and Atterberg limits of cohesive soils; Canadian Geotech. J. 42(2) 673-677.

Freedman D 2005 Statistical models: Theory and practice; Cambridge University Press, 245p.

Gan J K M and Fredlund D G 1988 Multistage direct shear testing of unsaturated soils; Am. Soc. Test. Mater. Geotech. Test. J. 11(2) 132-138.

Gibson R E 1953 Experimental determination of true cohesion and true angle of internal friction in clays; Proceedings of the 3rd International Conference on Soil Mechanics and Foundation Engineering, Zurich, pp. 1-126.

Holtz R D and Kovacs W D 1985 An Introduction to Geotechnical Engineering; Prentice-Hall, USA.

IAEG (International Association of Engineering Geology) 1976 Engineering geological maps: A guide to their preparation; The Unesco Press, Paris, pp. 1-79.

Kenney T C 1959 Discussion of Journal of the Soil Mechanics and Foundation Engineering Division; $A S C E$ 85-SM3 67-79.

Kenney T C 1967 The influence of mineral composition on the residual strength of natural soils; Proceedings of Oslo Conference on Shear Strength Properties of Natural Soils and Rocks 1 123-129.

Khallili N and Khabbaz M H 1998 A unique relationship for the determination of the shear strength of unsaturated soils; Geotechnique 48(5) 681-687.

Kurtuluş C, Sertçelik F, Canbay M and Sertçelik I 2009 Estimation of Atterberg limits and bulk mass density of Derince expansive soil from P-wave velocity measurements; 5th Congress of Balkan Geophysical Society, Belgrade, Serbia.

Lee J, Salgado R and Paik K 2003 Estimation of load capacity of pipe piles in sand based on CPT Results; J. Geotech. Geoenviron. Eng. 129(5) 391-403.

Leonards G A 1962 Foundation Engineering; Mc Graw Hill Book Company, New York, 1136p.

Leopold L B, Clarke F E, Hanshaw B B and Balsley J R 1971 A procedure for evaluating environment impact, Circular 645 , U.S. Geological Survey, 13p.

Linkov I, Varghese A, Jamil S, Seager T P, Kiker G and Bridges T 2004 Multi-criteria decision analysis: A framework for structuring remedial decisions at contaminated sites; In: Comparative Risk Assessment and Environmental Decision Making (eds) Linkov I and Ramadan A, Kluwer Publishers, pp. 15-54.

Luna R and Jadi H 2000 Determination of dynamic soil properties using geophysical methods; The First International Conference on the Application of Geophysical and NDT Methodologies to Transportation Facilities and Infrastructure; St. Louis.
Mc Bean E and Zukovs G 1983 A decision making analysis methodology for pollution control strategy formulation; Canadian Water Resour. J. 8(2) 64-67.

Miao L, Liu S and Lai Y 2002 Research of soil-water characteristics and shear strength feature of Nanyag expansive soil; Eng. Geol. 65 261-267.

Mitchell J K 1976 Fundamentals of Soil Behavior; John Wiley, New York, 422p.

Oberg A and Sallfors G 1997 Determination of shear strength parameters of unsaturated silts and sands based on the water retention curve; Geotech. Test. J. 20 40-48.

Odum E P, Bramlett G A, Ike A, Champlin J R, Zieman J C and Shugart H H 1976 Totality indices for evaluating environmental impact of highway alternatives; Transportation Research Rec. 561 56-57.

Poulos S J 1989 Liquefaction related phenomena; In: Advanced Dam Engineering for Design Construction and Rehabilitation Van Nostrand Reinhold (ed.) Jansen R B, pp. 292-320.

Saaty T L 1980 The analytic hierarchy process; McGrawHill, New York.

Saaty T and Millet I 2000 On the relativity of relative measures accommodating both rank preservation and rank reversals in the AHP; European J. Operational Res. 121 $205-212$.

Sawangsuriya A and Fratta D 2006 Discussion of correlations between P-wave velocity and Atterberg limits of cohesive soils; Canadian Geotech. J. 43 653-655.

Skempton A W 1953 The Colloidal activity of clays; Proc. 3rd Int. Conf. Soil Mechanics and Foundation Engineering (London) 1 47-61.

Skempton A W 1985 Residual strength of clays in landslides folded strata and the laboratory; Geotechnique 35 3-18.

Terzaghi K 1943 Theoretical Soil Mechanics; John Wiley and Sons, New York.

Van Der Merve D H 1964 The prediction of heave from the plasticity index and the percentage clay friction; South African Institute Civil Engineering 6 103-107.

Voight B 1973 Correlation between Atterberg plasticity limits and residual strength of natural soils; Geotechnique $\mathbf{2 3}$ $265-267$.

Wesley L D 2003 Residual strength of clays and correlation using Atterberg limits; Geotechnique 53(7) 669-672.

Whitlatch E E 1976 Systematic approaches to environmental impact assessment: An evaluation; Water Resour. Bull. 12(1) 123-137.

Wilbourn K, Vembu K and Vipulanandan C 2007 Index properties and strength of artificial soil using the Harvard miniature method; Final Report, Department of Environmental and Civil Engineering, University of Houston, USA.

Zadeh L and Tanaka K 1975 Fuzzy Sets and their Applications to Cognitive and Decision Processes; Academic Press, New York, 234p.

Zieman J C 1971 Optimum Pathway Matrix Analysis Approach to Environment Decision Making Process; Institute of Ecology, University of Georgia, Athens, Ga.12. 